\title{
Generalized Predictive Controller for Ball Mill Grinding Circuit in the Presence of Feed-grindability Variations
}

\author{
Sivanandam VENKATESH ${ }^{1}$, Kannan RAMKUMAR ${ }^{1}$, Muralidharan GURUPRASATH ${ }^{2}$, \\ Seshadhri SRINIVASAN ${ }^{3}$, Valentina E. BALAŞ ${ }^{4 *}$ \\ ${ }^{1}$ School of EEE, SASTRA University, \\ Thirumalaisamudram, Thanjavur, 613401, India \\ esvee@eie.sastra.edu, ramkumar@eie.sastra.edu \\ ${ }^{2}$ FLSmidth Pvt. Ltd, Cement and Minerals Projects India, \\ Chennai, 603 103, India \\ guruprasath.muralidharan@flsmidth.com \\ ${ }^{3}$ International Research Center, Kalasalingam University, \\ Srivilliputtur, India \\ seshucontrol@gmail.com \\ ${ }^{4}$ Aurel Vlaicu University of Arad, Romania \\ * Corresponding author: balas@drbalas.ro
}

\begin{abstract}
Feed-grindability variations (clinker hardness) in cement grinding circuit affects the product quality and productivity of the cement plant. This investigation proposes a generalized predictive controller for cement grinding circuit that is more robust to feed-grindability variations. The main building block of the proposed controller is a new model for cement grinding circuit that directly relates product quality with elevator current and main drive load. The advantage of the model is that the effect of feed-grindability variations on product quality can be easily observed from the output. To develop such a model, this investigation adapts a data driven modelling approach. Experimental data obtained as measurements from cement grinding circuit in a cement mill located near Chennai, India is used to develop the transfer function model based on least squares approach. The model obtained from data driven modelling is used to design a generalized predictive controller whose objective is to optimize the product quality in the presence of feed-grindability variations without breaching physical and operational limits of the cement grinding circuit. The tuning parameters of the proposed generalized predictive controller is adjusted to meet performance metrics specific to cement industries. Our results show that the proposed controller provides better product quality in the presence of feed-grindability variations than other optimization based controllers such as the linear quadratic regulator.
\end{abstract}

Keywords: Generalized Predictive Controller (GPC), cement grinding circuit, feed-grindability.

\section{Introduction}

Feed-grindability in cement grinding process denotes the ability of the clinker (the processed limestone from rotary kiln) to be broken down into smaller particles. Feed-grindability variations occur due to lack of homogeneity in clinkers procured from different vendors. Current practice in cement industries is to maintain the separator power constant and vary the separator speed for maintaining fineness [1]. This conventional way of controlling the fineness becomes ineffective beyond a particular operating range of separator when there are feed-grindability variations. Therefore, cement industries need control approaches that assure product quality in the presence of feed-grindability variations. The multi-variable nature and lack of models that relate feed-grindability variations with product quality (and production) make realizing such a controller challenging.
In literature, several control methods are studied for cement grinding circuit. The available methods can be broadly classified as: (i) classical [2]-[3], (ii) optimal [4]-[5], (iii) predictive $[6,8]$ and (iv) model-based controllers [9]. Classical controllers such as PID [2-3], state-feedback [7], and cascaded controllers [3] are used in cement industries for controlling the grinding process. Though, classical controllers are simple and cheap, they suffer from performance limitations arising from multi-variable interactions, model uncertainties, and actuator constraints. To overcome these shortcomings, linear quadratic (LQ) controllers were studied for cement grinding process in [4] and [5]. The LQ controllers showed better performance than classical controllers. However, the physical and operating constraints of the process were not considered in their design, thereby making their adaptation in cement industries difficult. Moreover, in these results the material 
accumulated inside the cement grinding mill that causes plugging phenomenon [6] has not been studied.

The investigations in [6] and [9] proposed a predictive controller for cement grinding circuit for handling the multivariable interactions and operating constraints. Results of these investigations showed that combining predictions with optimization driven control decisions leads to good tracking and regulatory performance. In spite of such advantages, their performance is limited by the model accuracy and uncertainties in the process. Motivated by this, Guruprasath et al. [1] studied the use of model predictive controllers (MPCs) for cement grinding circuit. The proposed controller was not only optimal, but also handled model complexities, and constraints, inherently in its design. Results of the investigation illustrated that the MPC provided better product quality and process performance. The performance enhancement is primarily due to the ability of MPCs to work closer to constraint boundaries and handle multi-variable interactions effectively. However, the proposed MPC approach cannot handle feed-grindability variations. A review of literature reveals that although, several approaches for controlling cement grinding circuit are available, these approaches are less robust to feed-grindability variations resulting in poor product quality and production rate. To overcome the shortcoming of existing literature, this investigation aims to design a predictive optimal controller that maintains product quality amidst feedgrindability variations. Furthermore, the controller should consider the physical and operating constraints in its design for being easily adapted in cement industries.

To reach the objectives, this investigation proposes a new model for cement grinding circuit that varies separator power by maintaining separator speed at its optimum efficiency. Next, the proposed model is used to design generalized predictive controller (GPC). The choice of GPC is dictated by its widespread acceptance in process industries, ability to deal with model complexities such as multivariable interactions, inherent constraint handling, and optimal performance. (see, [10][13] and references therein). Such properties are required for cement grinding circuit controllers to assure product quality in the presence of feed-grindability variations.
The main contributions of this investigation are: (i) a new data-based model for cement grinding circuit that relates elevator current and main drive load with product quality, (ii) GPC controller that uses the proposed model to optimize the product quality in the presence of feed-grindability variations, and (iii) illustration of the proposed controller in a cement industry and compare its performance with a linear quadratic regulator (LQR).

This paper is organized as follows. Section II discusses the ball mill cement grinding process. The idea behind the control strategy is discussed in section III. The data-driven transfer function model for the cement grinding circuit is presented in Section IV. Section V presents the GPC design for the cement grinding process. The performance of the proposed GPC is illustrated in Section VI. Conclusions and future prospects of the investigation are presented in Section VII.

\section{Cement Grinding Mill}

The schematic diagram of the finish milling circuit is shown in Figure 1. The feed to the finish milling are the clinkers (product from the rotary kiln of cement plant) that have varying grindability. The clinkers along with gypsum and fly ash enter the ball mill. The input material are grinded in the ball mill by the impact of steel or ceramic balls on the material. The grounded particles are lifted by the elevator to the separator that separates fine and coarse cement particles. The fine particles satisfying the desired fineness are sucked by the separator fan to the bag house for packing. The coarse particles gets collected as rejects at the bottom and is re-circulated into the ball mill for further grinding, thus forming a closed circuit. The manipulated variables viz., feed flow rate and separator fan power are actuated using the weigh feeder and servo potentiometer, respectively.

\section{Control Strategy}

Presence of right amount of material inside the ball mill improves efficient grinding of the clinkers. A lesser amount of material in the mill causes not only wear and tear of the equipment, but also reduces the productivity. On the contrary, a larger amount of material in the mill leads to the phenomenon called 'plugging' 


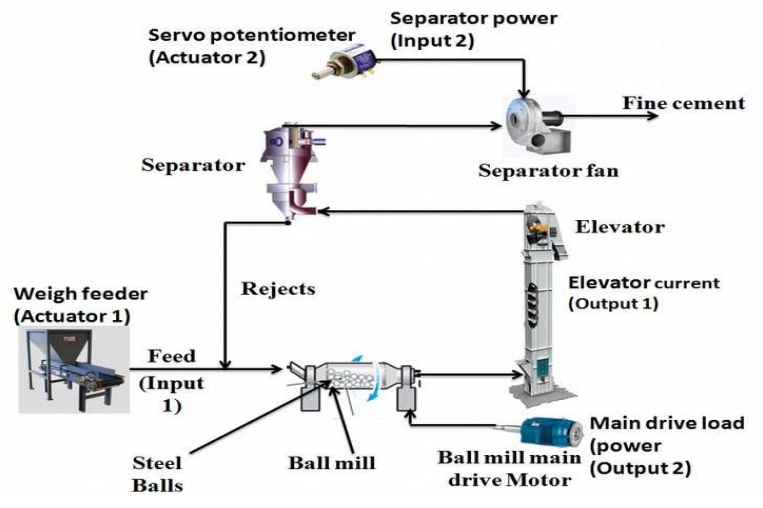

Figure 1. Schematic diagram of finish milling circuit

which causes the stoppage of the mill. The amount of material in the grinding circuit contributes to the grinding efficiency which inturn decides the fineness or the product quality. Consequently, to achieve better productivity with desired product quality and to operate the mill without interruption, a right amount of material inside the mill as well as in the circuit is necessary. As direct measurement of material inside the mill is not possible, cement industries employ indirect measurements.

The investigation in [1] exploited the correlation between elevator load and fineness to design a controller for cement grinding mill. The elevator load was varied by changing the feed-flow rate and separator speed. However, it is observed from our implementation that this approach fails to provide the desired product quality and productivity in the presence of feed-grindability variations due to saturation of the separator speed. To overcome this shortcoming with the control approach, this investigation uses the correlation between power consumed by the main motor and elevator with the material inside the ball mill to design a controller for maintaining fineness. To this extent, the investigation maintains the elevator current and main drive load at a set-point for achieving better product quality and productivity. To overcome the fluctuations in feed-grindability variations, a predictive controller approach is used to keep the separator speed at a set-point to guarantee fineness.

In order to design the predictive controller, the elevator current (in Amperes) and main drive load (in $\mathrm{kW}$ ) which provide direct measure of the product quality are used as the control variables. The feed-flow rate (Tones per Hour) and power consumed by the separator fan $(\mathrm{kW})$ are used as the manipulating variables to control the elevator current and main drive load. Currently, there are no models that relate the outputs (elevator current and main drive load) with the inputs (feed-flow rate and separator power). Obtaining a first principle model relating the variables of interest is cumbersome and costly for cement industries to develop. Therefore, this investigation uses a model driven approach. The real-time data collected from a cement grinding circuit near Chennai, India is used for building identifying the system model.

\section{Process Modelling}

This section describes the modelling procedure for cement grinding circuit. The cement grinding mill model that relates model of interest is multi-variable in nature. The elevator current is directly correlated with the amount of material inside the cement grinding mill or the material circulated. As shown earlier, the amount of material circulated in the cement grinding circuit is an indirect measure of the product quality. Whereas, the main drive load that provides an indirect measure of the amount of material inside the mill decides the productivity. Therefore, the outputs main drive load and elevator current denote the productivity and product quality directly. The inputs are feed-flow rate and separator power as explained in the previous section.

Usually, the cement grinding circuit model is nonlinear [1]. To design predictive controllers, the non-linear model is linearized around an operating point and then a controller is designed around that working region. This investigation uses the working region of the feed-flow rate (120-160 TPH) obtained from experiments as the optimum working range. This investigation uses the data obtained in this region to build a linear plant model. To obtain a linear model for the operating region of interest, data collected 
from a cement grinding circuit near Chennai using FLSmidth Pvt. Ltd., SCADA system is used as shown in Figure 2. The data are collected with a sample interval of 1 minute. The data thus collected by the SCADA system contains outliers and bad data that are eliminated using $\chi 2$ test [14]. Once the process data is removed of outliers, the next step is to obtain the model of cement grinding mill, data from the ball mill is first normalized and divided into training and testing data-sets. The normalized data is then used to obtain the transfer function model using system identification techniques based on least squares.

The transfer function thus obtained from the system identification toolbox is given in equation (1)

$$
\left[\begin{array}{l}
y_{1}(s) \\
y_{2}(s)
\end{array}\right]=\left[\begin{array}{cc}
\frac{0.5234 e^{-10 s}}{133 s+1} & \frac{-0.86 e^{-15 s}}{34.56 s+1} \\
\frac{-1.85 e^{-8 s}}{136 s+1} & \frac{1.96 e^{-15 s}}{4.95 s+1}
\end{array}\right]\left[\begin{array}{l}
u_{1}(s) \\
u_{2}(s)
\end{array}\right]
$$

The obtained model is validated against the actual data as shown in Figure 3. Our results show that the transfer function model provides a reasonable accuracy $( \pm 5 \%)$ in describing the input-output behavior of the cement grinding mill. The model thus obtained is more suitable for predictive controller design. This is mainly because, the GPC generally requires only a reasonable knowledge of process dynamics and is forgoing to modelling errors within a certain error range. The accuracy band obtained from our modelling approach is well within this bound and therefore, the model is used for designing the GPC. The discrete time counterpart of the continuous time model is given by sampling and discretizing the system leads to:

$$
\begin{aligned}
& {\left[\begin{array}{l}
y_{1}\left(z^{-1}\right) \\
y_{2}\left(z^{-1}\right)
\end{array}\right]=} \\
& =\left[\begin{array}{ll}
\frac{0.0003921}{1-0.9925 z^{-1}} z^{-10} & \frac{-0.02447}{1-0.9715 z^{-1}} z^{-15} \\
\frac{-0.01356}{1-0.9927 z^{-1}} z^{-8} & \frac{0.359}{1-0.8171 z^{-1}} z^{-15}
\end{array}\right]\left[\begin{array}{l}
u_{1}\left(z^{-1}\right) \\
u_{2}\left(z^{-1}\right)
\end{array}\right]
\end{aligned}
$$

The discrete-time model is used to obtain the controlled autoregressive and integrating moving average model (CARIMA) model due to its suitability to design GPC and the presence of integrator term in the model [15]. The structure of the CARIMA model is given by:

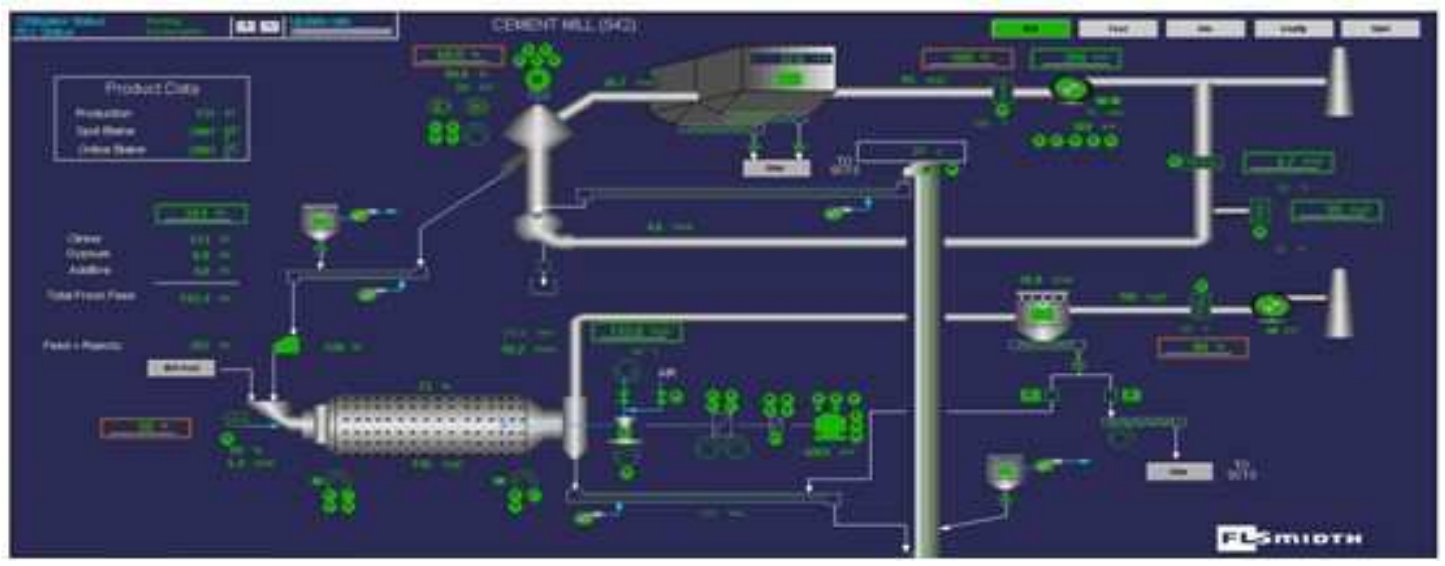

Figure 2. SCADA system to acquire the real time data from the plant
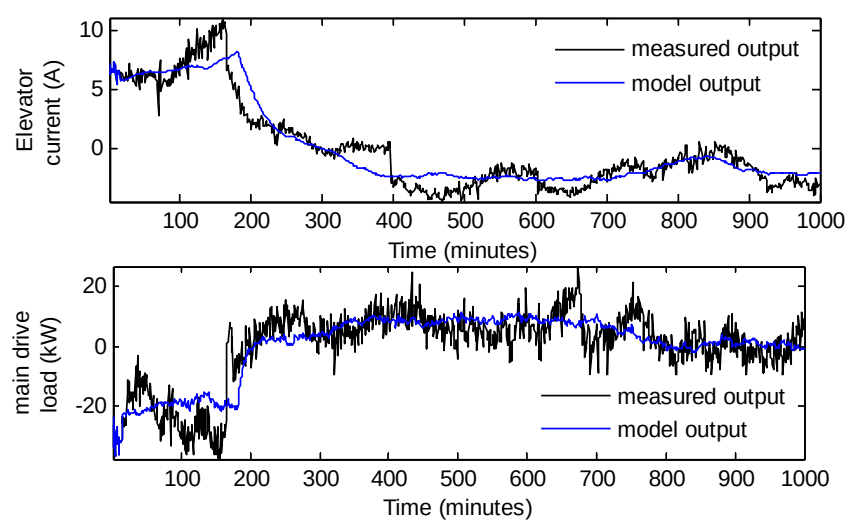

Figure 3. Model validation with observed data 


$$
a(z) y_{k}-b(z) u_{k}+t(z) \frac{\zeta_{k}}{\Delta}
$$

where $y_{k}$ is the output, $u_{k}$ is the input, $T(z)$ is the filter transfer function multiplied by to produce the disturbance term in the model, $\zeta_{k}$ is the zero mean uncorrelated variable and the $\Delta=1-z^{-1}$ is representing the differencing operator and $a(z), b(z)$ denote the numerator and denominator polynomials with coefficients $a_{1}, a_{2}, \ldots, a_{n}$ and $b_{1}, b_{2}, \ldots, b_{m}$ respectively. The subscript $n$ and $m$ are the length of denominator and numerator polynomial. The CARIMA model of the cement grinding circuit in (3) is modified as follows

$$
A(z) y_{z}=b(z) \Delta u_{k}
$$

where $A(z)=a(z) \Delta$.

The cement finish milling circuit is a multivariable system, hence matrix fraction description (MFD) is the popular representation of CARIMA as suggested in [16]. The $n \times m$ rational matrix representing the multivariable CARIMA model is given by

$$
G(z)=A(z) y_{k}+B(z) u_{k}
$$

\section{GPC Design for Cement Grinding Circuit}

The schematic of the proposed GPC for cement grinding process is shown in Figure 4 and nomenclature used in the section is given in Table 1. The GPC uses the model of the process, an optimization routine, estimate of the disturbances and knowledge of the constraints to generate the optimal control input that optimizes a given objective function. The objective function models the expected performance form the plant. The process model
Table 1. List of symbols used in the cement grinding process

\begin{tabular}{|c|c|}
\hline Symbols & Description \\
\hline$I_{E_{-} \text {ref }}$ & Elevator current - set point \\
\hline$P_{m \text { ref }}$ & Main drive load - set point \\
\hline$I_{E}$ & Elevator current- Actual \\
\hline$P_{m}$ & Main drive load - Actual \\
\hline$N_{p}$ & Prediction Horizon \\
\hline$N_{c}$ & Control Horizon \\
\hline$e$ & Error between set point and actual \\
\hline$u$ & Manipulating inputs \\
\hline
\end{tabular}

and disturbance estimate are used to predict future state of the process. Then an optimization routine is used to optimize a given objective function for the next $\mathrm{N}$ steps (called prediction horizon). In the cement grinding circuit, the feed-grindability variations enter as disturbances and are predicted as variations in elevator current. Corrective actions are then taken by the GPC to optimize the product quality in the presence of feed-grindability variations. In the rest of this section, we describe the formulation of the GPC.

The CARIMA model proposed in (5) can be used to generate one-step ahead prediction

$$
\begin{aligned}
& Y_{k+1}+A_{1} Y_{k}+\ldots+A_{n} Y_{k-n+1}= \\
& =B_{1} \Delta U_{k}+B_{2} \Delta U_{k-1}+\ldots+B_{m} \Delta U_{k-m+1}
\end{aligned}
$$

where $Y_{k}$ is the output containing two variables, the elevator current $y_{1 k}$ and the main drive load $y_{2 k}$. The incremental control input $\Delta U_{k}$ thus has two variables, feed flow rate $u_{1 k}$, and the separator power, $u_{2 k}$.

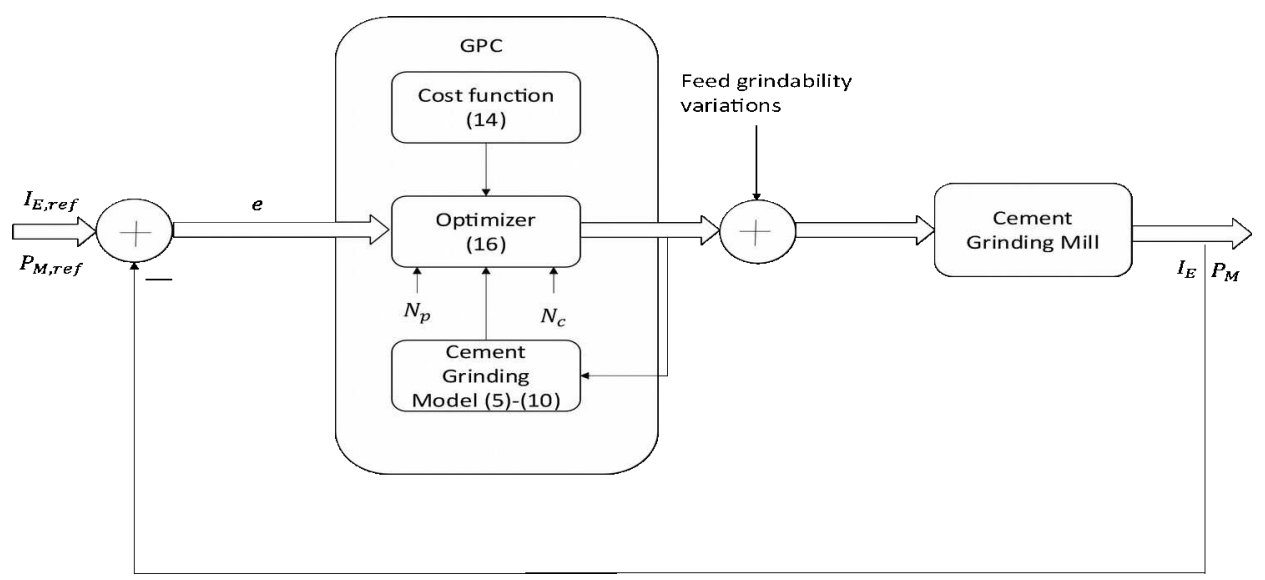

Figure 4. Schematic diagram of GPC implemented for the cement grinding process 
Equation (6) can be used to provide multi-step ahead prediction by extending the one-step aheadprediction to $\mathrm{N}$ steps, by constructing the prediction matrices:

$$
\begin{aligned}
& C_{A}\left[\begin{array}{l}
Y_{k+1} \\
Y_{k+2} \\
\vdots \\
Y_{k+N}
\end{array}\right]+H_{A}\left[\begin{array}{l}
Y_{k} \\
Y_{k-2} \\
\vdots \\
Y_{k-N+1}
\end{array}\right]= \\
& =C_{b}\left[\begin{array}{l}
\Delta U_{k} \\
\Delta U_{k+1} \\
\vdots \\
\Delta U_{k+N}
\end{array}\right]+H_{b}\left[\begin{array}{l}
\Delta U_{k-1} \\
\Delta U_{k-2} \\
\vdots \\
\Delta U_{k-N+1}
\end{array}\right]
\end{aligned}
$$

where $C_{A}, H_{A}$ and $C_{b}, H_{b}$ are matrices whose elements are the coefficients of the input and output polynomials that are representing the model parameters. The output prediction equation is obtained from (8) as

$$
Y_{k+1}+H \Delta U_{\rightarrow k}+P \Delta_{\leftarrow k-1}-Q Y \leftarrow k
$$

where $H, P, Q$ are the prediction matrices whose values are given as

$$
H=C_{A}^{-1} C_{b} ; \quad P=C_{A}^{-1} H_{b} ; \quad Q=C_{A}^{-1} H_{A}
$$

The right and left arrow notations in equation (8) represent the future and past variables, respectively.

The control input that optimizes the product quality in the presence of feed-grindability variations, the solution of the optimization problem:

$$
\min J=\sum_{k \in N_{c}} e_{K}+\lambda \Delta U_{k}
$$

Sub to:

$$
\begin{array}{ll}
e_{K}=r_{k+1-N_{c}}-Y_{k+1-N_{c}} & \\
\Delta U_{k}=U_{k+1}-U_{k} & \\
U_{k \min } \leq U_{k} \leq U_{k \max } ; & \forall k \in N_{c} \\
Y_{k \min } \leq Y_{k} \leq Y_{k \max } ; \quad \forall k \in N_{p} \\
\Delta U_{k \min } \leq \Delta U_{k} \leq \Delta U_{k \text { max }} ; \quad \forall k \in N_{c}
\end{array}
$$

where $\lambda$ is the tuning factor, $e_{K}$ is the difference between the reference trajectory and output, $N_{p}$ the prediction horizon, $N_{c}$ control horizon, respectively. The manipulating inputs denoted by $U_{k}$ are the feed flow rate $(F)$ and separator power $\left(P_{S}\right)$. The process outputs elevator current $I_{E}$ and main drive load $P_{m}$ denote the process outputs $Y_{k}$.
The physical constraints $Y_{k \text { min }}, \quad Y_{k \text { max }}$, $U_{k \min }, U_{k \max }$ denote the maximum and minimum bounds on the output and control input, respectively. The slew rate constraints on the input are given by $\Delta U_{k_{-} \min }, \Delta U_{k_{-} \max }$. Solution of the optimal control problem in (10)(11) computes the control input that optimizes the objective function in (10) while satisfying the constraints in (11), for the next $\mathrm{N}$ time-steps. The solution of the optimal control problem provides the control moves for the next $\mathrm{N}$ steps. The control moves are calculated as:

$$
\begin{aligned}
& \Delta U_{k}=\left(H^{T} H+\lambda I\right)^{-1} \\
& H^{T}\left[r_{\rightarrow k+1}-P \Delta U_{\leftarrow k-1}-Q Y_{\leftarrow k}\right]
\end{aligned}
$$

The first among the control moves is implemented and the rest of the $\mathrm{N}-1$ are discarded. The procedure is repeated during the next time period using the measurement. As decisions are made based on disturbance estimates and using an optimization routine, the cement grinding process is more robust to feedgrindability variations.

\section{Results and Discussion}

This section illustrates the performance of the proposed GPC for the cement grinding circuit in the presence of feed-grindability variations. The GPC performance is compared with the LQ controller to show the advantages of adapting it in cement industries. Two cases are studied to illustrate the benefits of GPC- low and high grindability feed variations. The performance of the GPC for variations in tuning parameter is also studied. Table 2 shows the test parameters of the GPC and the tuning parameter values that are used to avoid long settling times. The prediction and control horizons are selected based on the settling and delay time of the process (140 and 15 minutes, respectively) to predict the transient dynamics of the process.

\subsection{Performance of GPC with low grindability feed}

The performance of the designed GPC was tested in the cement grinding circuit by introducing grindability variations that is the hard clinker in the feed. The introduction of feed-grindability variations leads to variations in the process variables; thereby, affecting the steady state performance of the process. 
Table 2. Test parameters of GPC for cement grinding process.

\begin{tabular}{|c|c|c|c|}
\hline No. & Parameter & Description & Value \\
\hline 1 & $\begin{array}{l}\text { Prediction } \\
\text { horizon }\end{array}$ & & 150 \\
\hline 2 & $\begin{array}{l}\text { Control } \\
\text { horizon }\end{array}$ & & 20 \\
\hline 3 & $\begin{array}{l}\text { Tuning } \\
\text { parameter }(\lambda)\end{array}$ & & $0.7-1$ \\
\hline \multirow{2}{*}{4} & \multirow{2}{*}{$\begin{array}{l}\text { Constraints } \\
\text { (Upper limit) }\end{array}$} & Feed flow rate & $179.98 \mathrm{TPF}$ \\
\hline & & Separator power & $345.99 \mathrm{~kW}$ \\
\hline \multirow{2}{*}{5} & \multirow{2}{*}{$\begin{array}{l}\text { Constraints } \\
\text { (Lower limit) }\end{array}$} & Feed flow rate & $170.01 \mathrm{TPH}$ \\
\hline & & Separator power & $304.15 \mathrm{~kW}$ \\
\hline
\end{tabular}

Figure $5 \mathrm{a}$ and $5 \mathrm{~b}$ shows the performance of the GPC with low grindability feed (hard clinkers) that is introduced at the 200 time secs. The process variables elevator current and main drive load increases from the steady state values of $26 \mathrm{~A}$ and $1993 \mathrm{~kW}$, respectively. This may lead to the 'plugging' as explained earlier and can bring down the cement mill to grinding halt.

However, with the proposed GPC controller, the controlled variables are regulated to their steady-state values, this avoids excessive material in the mill and preventing plugging. The response of the controller for variations in tuning parameter $\lambda$ is analyzed and is shown in Figure $5 \mathrm{a}$ and $5 \mathrm{~b}$. It is evident from the Figure 5 a that increasing the tuning factor from 0.7 to 1 , the response of the process is speeded up. Consequently, there are drastic variations in the control input applied to the actuators to bring the process variables to steady state as shown in Figure 5b. Such fast changes are undesirable, and hence a tuning factor of 0.7 is selected. Figure 5 also shows that the separator power is reduced by using the proposed GPC. This result illustrates that the proposed GPC can handle low feed-grindability variations with additional benefits of achieving good product quality with low power consumption.

\subsection{Performance of GPC with high grindability feed}

The performance of the GPC controller for the higher grindability variations in the feed (soft clinkers) is also tested and analyzed. Figure 6a and $6 \mathrm{~b}$ show the variations of the output and input variables for high grindability feed is introduced at the 200-th sampling instant.
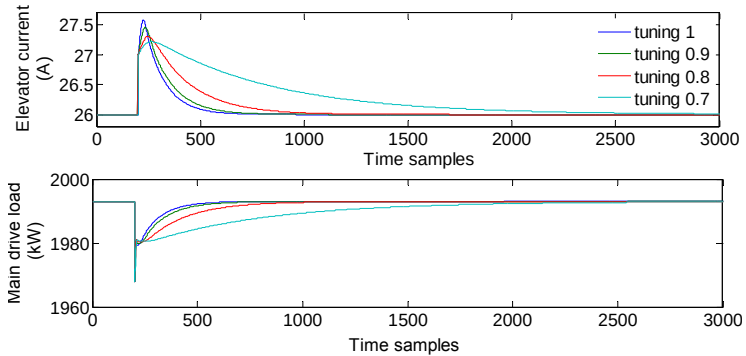

Figure 5a. Variations in process variables with different tuning factor under low grindability feed
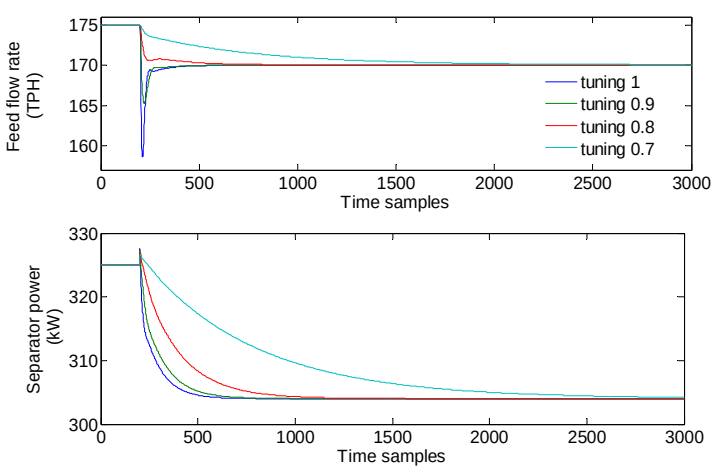

Figure 5b.Variations in manipulated variables with different tuning factor under low grindability feed
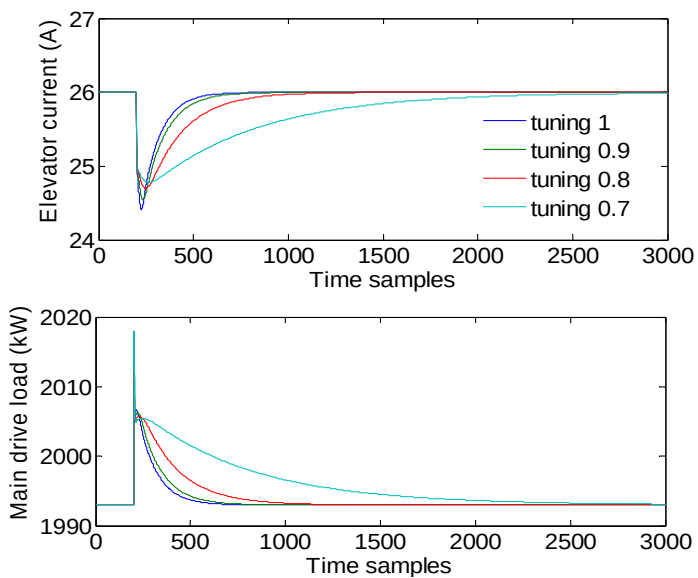

Figure 6a. Variations in process variables with different tuning factor under high grindability feed
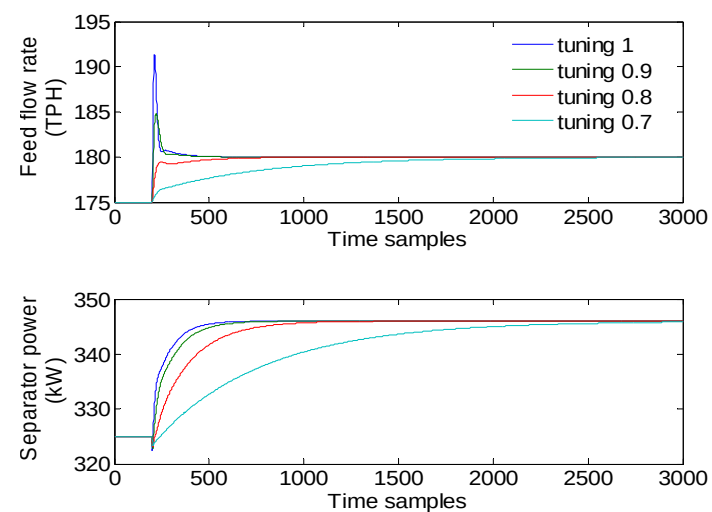

Figure 6b. Variations in manipulating variables with different tuning factor under high grindability feed 
This causes the elevator current to decrease as the rejects from the separator are reduced. Lowering the elevator current and main drive load causes wear and tear of the ball mill process. However, the GPC varies the manipulating variables to maintain the elevator current and main drive power to their steadystate values of (26A and $1993 \mathrm{~kW})$. Performance changes with tuning factor $\lambda$ is also studied. The controller performance varies with tuning factor as with low grindability feed. Using experiments, a tuning factor of 0.7 is selected as the performance improves both for low feed-grindability and high feedgrindability. Figures $6 \mathrm{a}$ and $6 \mathrm{~b}$ show the responses of process variables and controlled variables for high feed-grindability, respectively. Since the feed flow rate is increased during high feed-grindability conditions to maintain the elevator current as shown in Figure $6 \mathrm{~b}$, the product quality is maintained.

Table 3 shows the performance of the GPC for variations in the feed-grindability for different tuning factor. Performance metrics, integral square error (ISE), integral absolute error (IAE) and integral time absolute error (ITAE) are also shown. It can be observed that the performance metrics increases as the tuning parameter decreases. Further, the settling time also increases with the change in tuning parameter.

The manipulating bounds are also increased as the $\lambda$ value is increased. The rate of change of manipulations are also analyzed by finding their standard deviations which increases as the tuning factor increases.

From Table 4, it is evident that the limiting values of manipulating inputs, namely: feed flow rate and separator power, and their

Table 3. Performance metrics of GPC for different tuning parameter $\lambda$ for GPC implemented to cement grinding circuit.

\begin{tabular}{|c|c|c|c|c|c|c|c|c|c|c|c|c|}
\hline \multirow{2}{*}{$\lambda$} & \multicolumn{2}{|c|}{$\begin{array}{c}\text { Standard } \\
\text { deviations }\end{array}$} & \multicolumn{2}{|c|}{$\begin{array}{l}\text { Input } \\
\text { bounds }\end{array}$} & \multicolumn{4}{|c|}{$\mathbf{y}_{1}$ (Elevator current) } & \multicolumn{4}{|c|}{$\mathbf{y}_{2}$ (Main drive load) } \\
\hline & $\frac{d u_{1}}{d t}$ & $\frac{d u_{2}}{d t}$ & $\mathrm{~F}$ & $\mathrm{P}_{\mathrm{S}}$ & IAE & $\begin{array}{l}\text { ISE } \\
\times 10^{5}\end{array}$ & $\begin{array}{l}\text { ITAE } \\
\text { X } 10^{4}\end{array}$ & $t_{s}$ & $\begin{array}{l}\text { IAE } \\
\text { X } 10^{3}\end{array}$ & $\begin{array}{l}\text { ISE } \\
\times 10^{6}\end{array}$ & $\begin{array}{l}\text { ITAE } \\
\text { X } 10^{5}\end{array}$ & $t_{s}$ \\
\hline 1 & 0.136 & 0.089 & 17 & 23 & 188 & 0.35 & 5.668 & 349 & 1.59 & 2.55 & 4.72 & 337 \\
\hline 0.9 & 0.061 & 0.062 & 10 & 23 & 221 & 0.48 & 7.151 & 421 & 1.96 & 3.84 & 6.22 & 411 \\
\hline 0.8 & 0.019 & 0.039 & 5 & 22 & 333 & 1.11 & 13.44 & 687 & 3.15 & 9.94 & 12.47 & 691 \\
\hline 0.7 & 0.005 & 0.022 & 5 & 22 & 813 & 6.62 & 62.36 & 1911 & 8.21 & 67.43 & 62.24 & 1942 \\
\hline
\end{tabular}

$\frac{d u_{1}}{d t}, \frac{d u_{2}}{d t}$ Rate of change of inputs, F - Feed flow rate (TPH),

PS - Separator power (kW) ts` - a Response time (Time samples)

Table 4. Limiting values of manipulating inputs for different $\lambda$ values.

\begin{tabular}{|c|c|c|c|c|c|c|c|c|c|c|c|c|}
\hline$\lambda$ & \multicolumn{6}{|c|}{ Low grindability feed } & \multicolumn{5}{|c|}{ High grindability feed } \\
\hline & $\begin{array}{c}\min _{\mathrm{u}_{1}} \\
\begin{array}{c}\max \\
\mathrm{u}_{1}\end{array}\end{array} \begin{array}{c}\min \\
\mathrm{u}_{2}\end{array}$ & $\begin{array}{c}\max \\
\mathrm{u}_{2}\end{array}$ & $\begin{array}{c}\frac{d u_{1}}{d t} \\
\max \end{array}$ & $\frac{d u_{2}}{d t}$ & $\begin{array}{c}\min \\
\max \end{array}$ & $\begin{array}{c}\max \\
\mathrm{u}_{1}\end{array}$ & $\begin{array}{c}\min \\
\mathrm{u}_{2}\end{array}$ & $\begin{array}{c}\max \\
\mathrm{u}_{2}\end{array}$ & $\begin{array}{c}\frac{d u_{1}}{d t} \\
\max \end{array}$ & $\begin{array}{c}\frac{d u_{2}}{d t} \\
\max \end{array}$ \\
\hline 1 & 158 & 175 & 304 & 327 & 0.572 & 2.502 & 175 & 192 & 322 & 345 & 2.69 & 1.53 \\
\hline 0.9 & 165 & 175 & 304 & 327 & 0.152 & 1.760 & 175 & 185 & 322 & 345 & 1.00 & 0.75 \\
\hline 0.8 & 170 & 175 & 304 & 326 & 0.006 & 1.039 & 175 & 180 & 323 & 345 & 0.26 & 0.29 \\
\hline 0.7 & 170 & 175 & 304 & 326 & 0 & 0.545 & 175 & 180 & 323 & 345 & 0.06 & 0.09 \\
\hline
\end{tabular}

$\min \mathrm{u}_{1}$, $\max \mathrm{u}_{1}-$ Minimum and maximum values of feed flow rate.

$\min u_{2}, \max u_{2}-$ Minimum and maximum values of separator power.

$\frac{d u_{1}}{d t}$ Max, $\frac{d u_{2}}{d t} \max$ - Maximum rate of change of feed flow rate and separator power respectively 
Table 5. Error metrics for GPC and LQ controllers implemented for cement grinding circuit.

\begin{tabular}{|c|c|c|c|c|c|c|c|}
\hline \multirow{2}{*}{ SI.No } & \multirow{3}{*}{ Controller } & \multicolumn{4}{|c|}{ Y1 (Elevator current) } & \multicolumn{3}{c|}{ Y2 (Main drive load) } \\
\cline { 3 - 8 } & & IAE & $\begin{array}{c}\text { ISE } \\
\text { X } 10^{5}\end{array}$ & $\begin{array}{c}\text { ITAE } \\
\text { X } 10^{5}\end{array}$ & $\begin{array}{c}\text { IAE } \\
\text { X } 10^{3}\end{array}$ & $\begin{array}{c}\text { ISE } \\
\text { X } 10^{6}\end{array}$ & $\begin{array}{c}\text { ITAE } \\
\text { X } 10^{6}\end{array}$ \\
\hline 1 & GPC & 333.3155 & 1.1110 & 1.3446 & 3.1533 & 9.9433 & 1.2479 \\
\hline 2 & LQR & 559.7787 & 3.1335 & 1.8383 & 4.1570 & 17.281 & 1.3796 \\
\hline
\end{tabular}

maximum rate of change are decreasing with $\lambda$, which means that lower the $\lambda$ value lesser the manipulations and vice versa.

\subsection{Comparison of GPC with LQR controller}

The trade-off between the speed of response, manipulating bounds and their rate of change, forces to select the tuning value of 0.8 taking into account the plant nominal values. The resulting GPC controller is compared with the LQ controller. The results are shown in Figure 7. It is evident from the responses obtained with the two controllers, that the GPC shows better performance compared with LQ for both elevator current and main drive load in terms of lesser over shoot and speed of response. Furthermore, the performance metrics such as IAE, ISE and ITAE are better with GPC controller than LQ controllers as shown in Table 5.
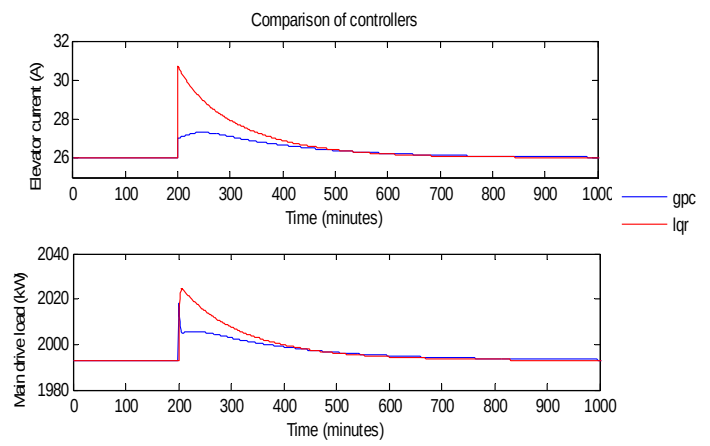

Figure: 7. Comparison of GPC and LQR controller implemented for the finish milling circuit in which the grindability variations are introduced at $200^{\text {th }}$ minute.

\section{Conclusions}

This paper presented a new model and a GPC controller for cement grinding mill that maintains product quality and productivity in the presence of feed grindability variations. First a model is proposed that maps the inputs (feed- flow rate and separator power) with the outputs (main drive load and elevator current). The proposed model directly relates the product and productivity with the inputs exploiting the correlation among the variables. To obtain the model, data collected from experiments on a cement grinding circuit in an Industry is used. The obtained model is used to design the GPC to control the cement grinding circuit. The designed controller directly mapped feed-flow rate and elevator current with product quality and productivity. The proposed controller was illustrated in a cement grinding mill for both high and low grindability variations. Further, the performance of the proposed GPC was compared with the LQR. Our results showed that the proposed GPC works equally well for both high and low grindability variations. Furthermore, our results demonstrated that the proposed GPC is better than the LQR controller proposed in literature. The proposed GPC enhances the product quality and productivity in a cement grinding mill. Implementing robust GPC and analysing its performance in industries is the future work of this investigation.

\section{REFERENCES}

1. PRASATH, G., B. RECKE, M. CHIDAMBARAM, J. B. JØRGENSEN, Soft Constrained Based MPC for Robust Control of a Cement Grinding Circuit, Preprints of the 10-th IFAC International Symposium on Dynamics and Control of Process Systems, The International Federation of Automatic Control, Mumbai, India, Dec. 18-20, 2013.

2. POMERLEAU, A., D. HODOUIN, A. DESBIENS, E. GAGNON, A Survey of Grinding Circuit Control Methods: From Decentralized PID Controllers to Multivariable Predictive Controllers, Powder Technology, Elsevier, vol. 108, no. 2-3, 2000, pp. 103-115. 
3. BOULVIN, M., A. VANDE WOUWER, Modeling and Control of Cement Grinding Processes, IEEE Transactions On Control Systems Technology, IEEE, vol. 11, no 5, 2003, pp. 715-725.

4. VAN BREUSEGEM, V., L. CHEN, G. BASTIN, V. WERTZ, V. WERBROUCK, C. DE PIERPONT., An Industrial Application of Multivariable Linear Quadratic Control to a Cement Mill Circuit, IEEE Transactions On Industry Applications, IEEE, vol. 32, no. 3, 1996, pp. 670 -677.

5. BOULVIN, M., C. RENOTTE, A. VANDE WOUVER, M. REMY, S. TARASIEWICZ, P. CESAR, Modeling, Simulation and Evaluation of Control Loops for a Cement Grinding Process, European Journal of Control, Elsevier, vol. 5, 1999, pp. $10-18$.

6. MAGNI, L., G. BASTIN, V. WERTZ, Multivariable Non linear Predictive Control of Cement Mills, IEEE Transactions on Control Systems Technology, vol. 7, 1999, pp. 502-508.

7. GROGNARD, F., F. JADOT, L. MAGNI, G. BASTIN, R. SEPULCHRE, V. WERTZ, Robust Stabilization of a Nonlinear Cement Mill Model, IEEE Transactions On Automatic Control, IEEE, vol. 46, no. 4, 2001, pp. 618-623.

8. MARTIN, G., S. MCGAREL, Nonlinear Mill Control, ISA Transactions, Elsevier, vol. 40, no. 4, 2001, pp. 369-379.

9. LIU, Z., Q. YANG, W. YAN, Intelligent Modeling And Predictive Control of PreGrinding System, Advanced Materials Research, Trans Tech Publications, vol. 433440, 2012, pp. 2120-2127.
10. WEN, S., J. ZHU, X., LI, S. H., CHEN, A Double-loop Structure in the Adaptive Generalized Predictive Control Algorithm for Control of Robot end-Point Contact Force, ISA Transactions, Elsevier, vol. 53, no. 5, 2014, pp. 1603-1608.

11. YANFEI, Y., W. BAILIN, S. MINGHENG, Z. YONGQI, Polymerizer Temperature Cascade Control System Based on Generalized Predictive Control, Physics Procedia, Elsevier, vol. 24, Part A, 2012, pp. 184-189.

12. CLARKE, D. W., C. MOHTADI, P. S. TUFFS, Generalized Predictive Control Part I. The Basic Algorithm, Automatica, Elsevier, vol. 23, no. 2, 1987, pp. 137-148.

13. MUTHUKUMAR., N., SESHADHRI SRINIVASAN, K., RANKUMAR, P., KAVITHA, V. E., BALAŞ, Supervisory GPC and Evolutionary PI Controller for Web Transport Systems, Acta Polytechnical Hungarica, accepted for publication, 2015.

14. NING, Y.-Y., Z. WANG, M.-Z. YUAN, Z.$\mathrm{H}$. LI, Intelligent Control Based on Casebased Reasoning for Fineness of Raw, Zhongnan Daxue Xuebao (Ziran Kexue Ban)/Journal of Central South University (Science and Technology), Central South University of Technology, vol. 42 (SUPPL. 1), 2011, pp. 918-923.

15. ROSSITER, J. A., Model-based Predictive Control: A Practical Approach, Control Series, CRC Press, 2005.

16. CAMACHO, E. F., C. BORDONS, Model Predictive Control, Springer-Verlag London Limited, Great Britain. 